\title{
High-density lipoprotein concentrations increase after stopping smoking
}

\author{
INGO STUBBE, JAN ESKILSSON, PETER NILSSON-EHLE
}

\begin{abstract}
Concentrations of plasma lipoproteins in 10 men who were habitual smokers were monitored for six weeks after they stopped smoking and related to changes in diet and body weight. The energy intake increased by $10 \%$ $(\mathbf{p}<0.05)$ owing to a higher consumption of carbohydrate and fat, and body weight increased by $2 \%(p<0.01)$. Plasma triglyceride, cholesterol, and low-density lipoprotein cholesterol concentrations did not change significantly.

The most prominent finding was a rapid and pronounced increase in high-density lipoprotein concentrations. From comparatively low values (mean $0.82 \mathrm{mmol} /$ 1) they rose by $29 \%(p<0.01)$ within two weeks and remained at this value throughout the observation period. In three subjects who resumed smoking after the end of the study they again fell to initial values six weeks later. The initial increase in concentration could be accounted for mainly by an increase in the esterified fraction and only to a lesser extent in the free cholesterol fraction. The changes in concentration were accompanied by similar but less pronounced rises in high-density lipoprotein phospholipid and in apolipoprotein AI concentrations $(p<0.01)$, whereas high-density lipoprotein triglyceride concentrations did not change significantly.

These findings confirm and extend those of earlier cross-sectional studies which showed low concentrations of high-density lipoproteins in cigarette smokers. A significant correlation between the rise in high-density lipoprotein cholesterol concentrations and the increase
\end{abstract}

\footnotetext{
Departments of Cardiology and Clinical Chemistry, University Hospital, Lund, Sweden

INGO STUBBE, MD, senior registrar in cardiology

JAN ESKILSSON, MD, senior registrar in cardiology

PETER NILSSON-EHLE, MD, PHD, associate professor of clinical chemistry
}

in fat consumption after stopping smoking indicate that the changes in high-density lipoprotein concentrations may be partly due to nutritional factors.

\section{Introduction}

The association between cigarette smoking and coronary heart disease is well established, ${ }^{1-4}$ but the mechanisms by which smoking harms the heart are poorly understood. ${ }^{56}$ One of the factors which may increase the risk of coronary heart disease is the low concentration of high-density lipoprotein found in cigarette smokers. ${ }^{7-9}$

To assess further the relationship between smoking and plasma lipoprotein concentrations we have monitored the timecourse for changes in lipoprotein concentrations after subjects stop smoking completely and related these to changes in diet and body weight.

\section{Subjects and methods}

Twenty-one male smokers, recruited by advertising in the local hospital bulletin, were included in the study and 10 of them succeeded in abstaining from smoking during the observation period of six weeks. Their age range was 32-50 (mean 38) years and weight 64-100 (mean 77) kg. All had been heavy smokers for at least 12 years with a consumption of 17-30 (mean 21) cigarettes a day. They had normal Swedish dietary habits, and none was engaged in regular physical activities. All felt well, and none took any medication. Routine laboratory tests showed no signs of renal, hepatic, or metabolic disorders.

While abstaining from smoking the subjects were supported psychologically by a team from the hospital's smoking withdrawal clinic, but no medication was given. Dietary habits were registered by a clinical nutritionist, who obtained a careful dietary history both during and at the end of the study. ${ }^{10}$ The food composition tables edited by the Swedish National Food Administration were used to calculate the proportions of fat, protein, and carbohydrates.

Blood samples taken after one, two, four, and six weeks were collected in the morning, after the subjects had been fasting for at least 10 hours. The initial values represented the mean of two samples drawn at one week and at three days before stopping smoking. 
The lipid components of high-density lipoprotein were determined in the supernatant obtained after precipitation of very low-density lipoprotein and low-density lipoprotein by magnesium chloride and dextran sulphate. ${ }^{11}$ Cholesterol and triglycerides were determined by enzymatic methods ${ }^{11-13}$; free and esterified cholesterol were differentiated by measurements with and without the cholesterol esterase reagent. Phospholipids were measured as lipid phosphorus. Apolipoprotein AI was measured in plasma by electroimmunoassay. ${ }^{14}$ Low-density lipoprotein cholesterol was calculated according to the formula of Friedewald. ${ }^{15}$

The significance of changes in different variables was evaluated using Wilcoxon's rank order test for paired observations. Correlations between variables were analysed by linear regression analysis.

\section{Results}

Carboxyhaemoglobin concentrations were raised before stopping smoking (3.4 $\pm 1 \cdot 0 \%$, mean $\pm S D)$ and fell to below $1 \%$ within one week after stopping smoking. The initial concentrations of carboxyhaemoglobin were correlated with the number of cigarettes smoked $(r=0.68 ; p<0.05)$, but there was no correlation between these two variables and the initial concentrations of high-density lipoprotein cholesterol or apolipoprotein AI.

A small transient decrease of about $5 \%$ occurred in haemoglobin concentrations, red blood cell count, and packed cell volume during the first two weeks $(p<0.01)$, but all values were in the upper part of the reference range (initial mean haemoglobin concentration was $14 \cdot 4 \mathrm{~g} / \mathrm{dl})$.

The concentrations of plasma proteins, albumin, $\alpha_{1}$-antitrypsin, orosomucoid, haptoglobin, ceruloplasmin, and IgG did not change, but IgA concentrations decreased by about $20^{\circ} \%(\mathrm{p}<0.01)$.

The initial mean energy intake was 11676 (range 7896-18 564) kJ per day consisting of $16 \%$ protein, $39 \%$ fat, $42 \%$ carbohydrates, and $3 \%$ alcohol. After stopping smoking the mean energy intake increased by $9 \%$ after three weeks $(\mathrm{p}<0.05)$ and was about $7 \%$ above initial values at the end of the study (not significant). This increase could be accounted for by a higher consumption of carbohydrates and fat $(+10 \%$ and $+9 \%, p<0.05$ after three weeks). Alcohol intake did not change in the middle of the observation period and decreased slightly by about $9 \%$ (not significant) at the end of the study. Body weight increased by a mean of $1.8 \mathrm{~kg}$ or $2 \%(\mathrm{p}<0.01)$. The physical activity of the subjects, assessed by detailed interview, did not change during the study.

The most prominent change in the plasma lipid and lipoprotein concentrations was a rapid and pronounced rise in high-density lipoprotein concentrations after stopping smoking. From comparatively low values (mean $0.82 \mathrm{mmol} / 1$, lower reference limit $0.8 \mathrm{mmol} / \mathrm{l}$ ) concentrations gradually increased and reached a plateau $29 \%$ above initial values $(\mathrm{p}<0.01)$ after two weeks (fig 1$)$. Individual

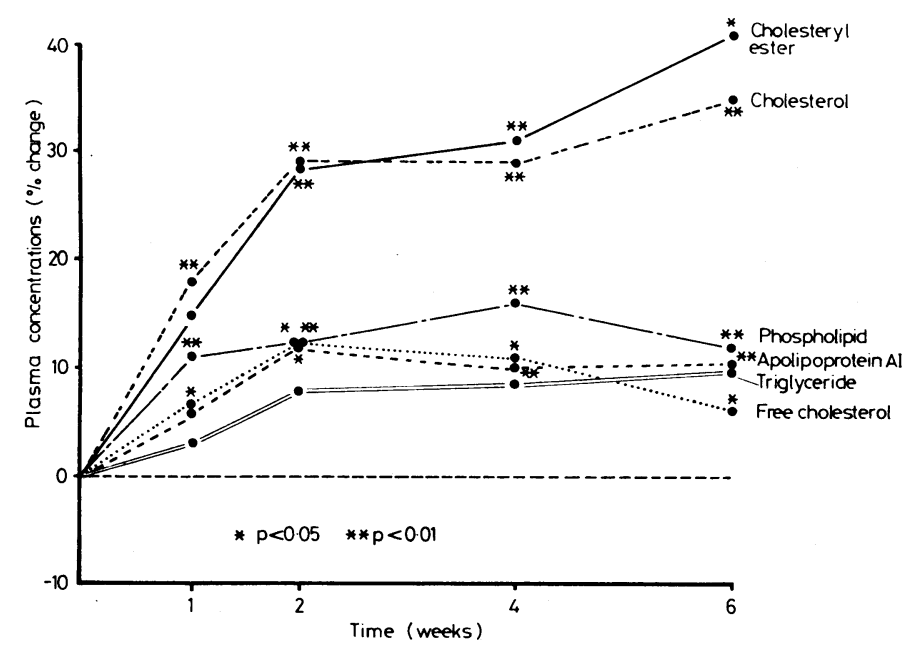

FIG 1-Relative changes in high-density lipoprotein (HDL) constituents after stopping smoking. Initial values (mmol/l, mean $\pm \mathrm{SEM}$ ) were: cholesteryl ester, $0.61+0.06$, free cholesterol $0.21 \pm 0.01$, total cholesterol, $0 \cdot 82 \pm 0.04$, phospholipid, $0.95 \pm 0.04$, triglyceride, $0 \cdot 20 \pm 0.01$, and apolipoprotein AI ( \% mean \pm SEM), $94 \pm 4$. initial and maximum concentrations are shown in table $I$. The rise in high-density lipoprotein cholesterol concentrations was associated with a transient moderate increase in plasma cholesterol concentrations of about $7 \%(\mathrm{p}<0.01)$ during the first two weeks. Low-density lipoprotein cholesterol concentrations remained unchanged. Plasma triglyceride concentrations, essentially reflecting very-low-density lipoprotein concentrations in these normolipaemic subjects, were constant up to four weeks after stopping smoking but increased by about $21 \%(\mathrm{p}<0.05)$ after six weeks.

TABLE I-Increase in high-density lipoprotein (HDL) cholesterol concentrations after stopping smoking in 10 subjects

\begin{tabular}{|c|c|c|c|}
\hline \multirow{2}{*}{ Case No } & \multicolumn{2}{|c|}{ HDL cholesterol concentrations $(\mathrm{mmol} / \mathrm{l})$} & \multirow{2}{*}{$\begin{array}{l}\text { Time of maximum } \\
\text { change (weeks) }\end{array}$} \\
\hline & Initial & Maximum & \\
\hline 1 & 0.85 & $1 \cdot 10$ & 6 \\
\hline 2 & 0.65 & $1 \cdot 10$ & 6 \\
\hline 3 & 0.80 & $1 \cdot 10$ & 6 \\
\hline 4 & 0.70 & 1.40 & 6 \\
\hline 5 & 0.85 & $1 \cdot 10$ & 4 \\
\hline 6 & 0.75 & 1.30 & 6 \\
\hline 7 & 1.05 & $1 \cdot 20$ & 6 \\
\hline 8 & 0.90 & 1.20 & 2 \\
\hline 9 & 0.75 & 0.90 & 4 \\
\hline 10 & 0.85 & 1.40 & 6 \\
\hline Mean $( \pm \operatorname{SEM})$ & $0.82(0.036)$ & $1.18(0.049)$ & \\
\hline
\end{tabular}

Three of the subjects resumed smoking after six weeks of abstinence. Their initial high-density lipoprotein cholesterol concentrations were $0.75-0.92$ (mean 0.82 ) $\mathrm{mmol} / \mathrm{l}$ and increased by about $13 \%$, $24 \%, 22 \%$, and $33 \%$ after one, two, four, and six weeks respectively. Four weeks after they resumed smoking the concentrations had again decreased and were only $8 \%$ above the initial values.

The rise in high-density lipoprotein was reflected in all its major components, which increased simultaneously but to varying degrees during the first two weeks after stopping smoking (fig 1). The increase in high-density lipoprotein cholesterol was mainly due to an increase in the esterified cholesterol fraction, about $41 \%$ at the end of the study $(p<0.05)$, whereas the free cholesterol fraction increased by only $10^{\circ} \%(p<0.05)$, a rise similar to that for high-density lipoprotein phospholipids $(p<0.01)$. The only lipid constituent of high-density lipoprotein that did not change significantly was the triglyceride component. The protein moiety of high-density lipoprotein, monitored by concentrations of apolipoprotein AI, increased by about $10 \%(\mathrm{p}<0.01)$.

As a result of the differential changes in high-density lipoprotein components, the composition of the high-density lipoprotein particles changed significantly after stopping smoking. The ratio of apolipoprotein AI to high-density lipoprotein cholesterol fell by $11 \%$ $(p<0.05)$ after two weeks, suggesting a preferential increase in the lipid-rich high-density lipoproteins particles. A comparison of the lipid composition of high-density lipoprotein before and after stopping smoking is given in table II. Most prominently, the cholesteryl

TABLE II-Percentage lipid composition of high-density lipoprotein before and six weeks after stopping smoking in 10 subjects (w/v; means 1 SEM)

\begin{tabular}{lccccc}
\hline & $\begin{array}{c}\text { Total } \\
\text { cholesterol }\end{array}$ & $\begin{array}{c}\text { Cholesteryl } \\
\text { ester }\end{array}$ & $\begin{array}{c}\text { Free } \\
\text { cholesterol }\end{array}$ & Phospholipid & $\begin{array}{c}\text { Plasma } \\
\text { triglyceride }\end{array}$ \\
\hline Before & $33 \cdot 6+1 \cdot 2$ & $27 \cdot 5 \pm 1 \cdot 4$ & $6 \cdot 1+0 \cdot 4$ & $53 \cdot 6 \pm 0 \cdot 8$ & $12 \cdot 8+0 \cdot 6$ \\
After six weeks & $38 \cdot 6+1 \cdot 8^{*}$ & $32 \cdot 8+1 \cdot 9^{*}$ & $5 \cdot 8 \pm 0 \cdot 3$ & $50 \cdot 8 \pm 1 \cdot 4$ & $10 \cdot 6 \pm 0 \cdot 6$
\end{tabular}

${ }^{*} \mathrm{p}<0.05$.

ester fraction increased by $13-19^{\circ},(p<0.05)$ and constituted significantly more $(5 \cdot 3 \%)$ of the lipid moiety of high-density lipoprotein. This expansion occurred at the expense of all other lipid components but mainly resulted in a reduction of the proportion of the other core component, the triglyceride.

The nature of the increase in high-density lipoprotein was further investigated by statistical analysis of the relationship between highdensity lipoprotein components and other lipids and lipoproteins as well as dietary constituents; both absolute values of these variables and changes occurring after stopping smoking have been analysed 
by linear regression. No significant relationships were found between high-density lipoprotein concentrations and other plasma lipids and lipoproteins. There were no significant correlations between changes in carboxyhaemoglobin concentrations, body weight, or carbohydrate or alcohol consumption on the one hand and high-density lipoprotein concentrations on the other. The increase in fat ingestion was, however, significantly correlated with the rise in high-density lipoprotein cholesterol $(r=0.73, p<0.01)$ (fig 2).

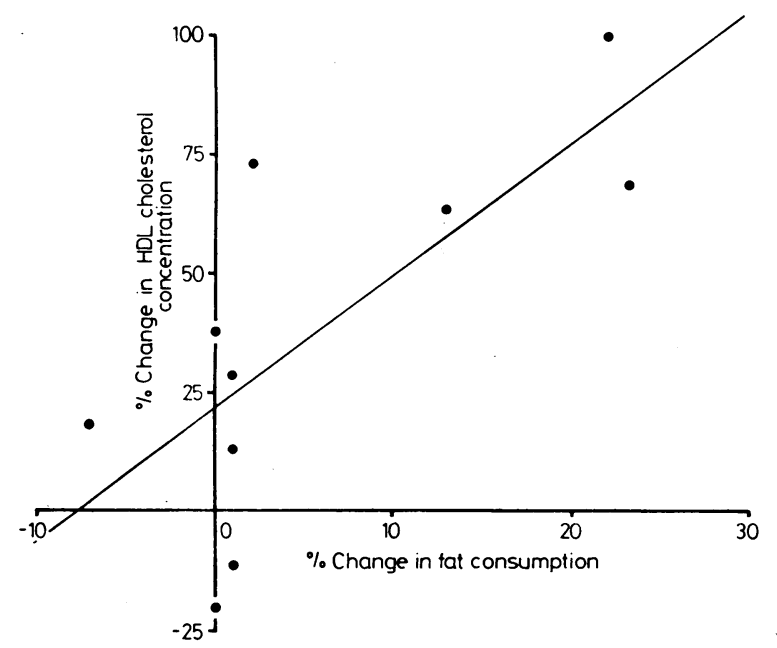

FIG 2-Linear regression of relative changes in dietary fat intake and high-density lipoprotein (HDL) cholesterol concentrations. Regression equation, $y=2 \cdot 8+21 \cdot 8$; correlation coefficient 0.73 $(\mathrm{p}<0.01)$.

\section{Discussion}

Cigarette smoking is one of the major risk factors in coronary heart disease.$^{1-4}$ Several mechanisms have been suggested to explain the harmful effects of cigarette smoking on cardiovascular health ${ }^{5}$; several recent studies have focused on changes in the lipoprotein profile as possible reasons. In several comparative studies of smokers and non-smokers, smokers have had significantly lower high-density lipoprotein concentrations, measured as high-density lipoprotein cholesterol ${ }^{7-9}$ or as apolipoprotein $\mathrm{AI}^{16}$; in some studies, moderately raised low-density lipoprotein concentrations have also been found. ${ }^{17} 18$ To clarify further the relation between smoking and changes in lipoprotein values, we have monitored the time-course of changes in lipoprotein concentrations, particularly those of highdensity lipoprotein and its constituents, in 10 heavy smokers who stopped smoking completely.

In agreement with earlier findings, our subjects had remarkably low concentrations of high-density lipoprotein cholesterol and apolipoprotein AI before stopping smoking. In fact, five out of the 10 participants had high-density lipoprotein cholesterol concentrations below the lower reference limit $(0.8 \mathrm{mmol} / \mathrm{l})$. With the limited number of subjects, no significant relation between carboxyhaemoglobin concentrations or cigarette consumption and high-density lipoprotein concentrations could be shown. ${ }^{8}$ The initial low-density lipoprotein concentrations recorded in our study were not higher than normal. ${ }^{17} 18$

The participants in the study were encouraged to keep their habits and physical activities as constant as possible after stopping smoking. Nevertheless, almost all increased their consumption of fat and carbohydrate by about $7-10 \%$, but the weight gain (mean $1.8 \mathrm{~kg}$ over six weeks) was less pronounced than usually recorded. ${ }^{19}$ Alcohol intake, which rapidly raises high-density lipoprotein concentrations, ${ }^{20}$ fell towards the end of the study.

Except for the minor triglyceride component, all constituents of the high-density lipoprotein fraction increased significantly by $10-15 \%$ for apolipoprotein AI, phospholipid, and free cholesterol. Nevertheless, the major component, cholesteryl ester, increased by more than $40 \%$. The corresponding changes in high-density lipoprotein composition suggest that a shift in the ratio of high-density lipoprotein ${ }_{2}$ to high-density lipo-

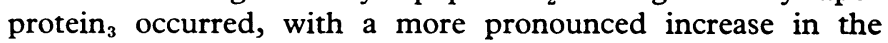
lipid-rich high-density lipoprotein particles. $_{2}$

The close relation between smoking and high-density lipoprotein concentrations is further illustrated by the fact that in those subjects who resumed smoking after the end of the study concentrations rapidly returned to the low initial values. The mechanisms responsible for the pronounced increase in high-density lipoprotein concentrations remain unclear. Nevertheless, the correlation between the increase in fat intake and rise in high-density lipoprotein cholesterol concentrations indicates that the changes in lipoprotein concentrations after stopping smoking may be partly related to nutritional changes.

We thank Mrs Carin Andersson for expert dietary analyses and Miss Gerd Nilsson for skilful technical help. This study was supported by grants from the Swedish Medical Research Council (04966) and Påhlsson's Foundation, Malmö.

\section{References}

1 Doll R, Hill AB. Mortality in relation to smoking: ten years' observations of British doctors. Br Med $\mathcal{F} 1964 ; \mathrm{i}: 1399-410$.

2 Hammond EC. Smoking in relation to the death rate of one million men and women. Natl Cancer Inst Monogr No 19. Bethesda, Maryland: National Cancer Institute, 1966:127-204.

${ }^{3} \mathrm{Kahn}$ HA. The Dorn study of smoking and mortality among US veterans: Report of eight and one-half years' of observation. Natl Cancer Inst Monogr No 19. Bethesda, Maryland: National Cancer Institute, 1966:1.

${ }^{4}$ Gordon T, Kannel WB, McGee D. Death and coronary attacks in men after giving up cigarette smoking: A report from the Framingham Study. Lancet 1974;ii:1345-8.

${ }^{5}$ Ball K, Turner R. Smoking and the heart: The basis for action. Lancet 1974 ;ii :822-6.

${ }^{6}$ Anonymous. How does smoking harm the heart ? Br Medf $1980 ; 281$ :573-4.

Goldbourt U, Medalie JH. Characteristics of smokers, non-smokers, and ex-smokers among 10000 males in Israel. II Physiological, biochemical and genetic characteristics. Am 7 Epidemiol 1977;105:75-86.

${ }^{8}$ Criqui MH, Wallace RB, Heiss G, Mishkel M, Shonfeld G, Jones GTL. Cigarette smoking and plasma high density lipoprotein cholesterol: The lipid research clinics program prevalence study. Circulation $1980 ; 62$ suppl 4:70-6.

${ }^{9}$ Garrison RJ, Kannel WB, Feinleib M, Castelli MP, McNamara PM, Padgett SJ. Cigarette smoking and HDL cholesterol: The Framingham offspring study. Atherosclerosis $1978 ; 30: 17-25$.

${ }^{10}$ Isaksson B. Urinary nitrogen output as a validity test in dietary surveys. Am 7 Clin Nutr 1980;33:4-5.

11 Danielsson B, Ekman R, Fex G, et al. Changes in plasma high density lipoproteins in chronic male alcoholics during and after abuse. Scand f Clin Lab Invest 1978 ;38:113-9.

${ }^{12}$ Roeschlau P, Bernt E, Gruber W. Enzymatische Bestimmungen des Gesamtcholesterin im Serum. $Z$ Klin Chem 1974;12:226-30.

13 Wahlefeld $\mathrm{AW}$. Triglyceride determination after enzymatic hydrolysis. In: Bergmeyer HU, ed. Methods of enzymatic analysis, 2nd ed. Weinheim: Verlag Chemie, and New York: Academic Press, 1974.

14 Laurell CB. Electroimmunoassay. Scand $\mathcal{f}$ Clin Lab Invest $1972 ; 29$ suppl $124: 21-9$.

${ }^{15}$ Friedewald WT, Levy RI, Fredrickson DS. Estimation of the concentration of low density lipoprotein cholesterol without use of the preparative ultracentrifuge. Clin Chem 1972;18:499-506.

16 Berg K, Börresen AL, Dahlen G. Effect of smoking on serum levels of HDI apoproteins. Atherosclerosis 1979;34:399-43.

17 Boyle E, Morales IB, Nichaman MZ, Talbert RC, Watkins RS. Serum beta lipoproteins and cholesterol in adult men: relationships to smoking, age and body weight. Geriatrics $1968 ; 23: 102-11$.

18 Billimoria JD, Pozner H, Metselaar B, Best FW, James DCO. Effect of cigarette smoking on lipids, lipoproteins, blood coagulation, fibrinolysis, and cellular components of human blood. Atherosclerosis 1975;21:61-76.

19 Blitzer PH, Rimm AA, Giefer EE. The effect of cessation of smoking on body weight in 57032 women: cross-sectional and longitudinal analyses. f Chron Dis $1977 ; 30: 415-29$.

20 Pelfrage $P$, Nilsson-Ehle $P$, Wiebe $T$. Prolonged administration of ethanol to young healthy volunteers: effect on biochemical, morphological and neurophysiological parameters. Acta Med Scand 1973;4 suppl 552:19-26.

(Accepted 1 March 1982) 